Archived version from NCDOCKS Institutional Repository http://libres.uncg.edu/ir/asu/

Schilbrack, Kevin. 2012. "New directions for philosophy of religion: four proposals." Studies In Religion/Sciences Religieuses 41, no. 1: 46-56. (March 2012) [ISSN: 0008-4298] [DOI: 10.1177/0008429811430058] The version of record is available from Sage Publications http://sir.sagepub.com/

\title{
New Directions for Philosophy of Religion: Four Proposals Kevin Schilbrack
}

\begin{abstract}
This set of papers explores the topic of "Possible Futures for Philosophy of Religion." Though the field of philosophy of religion today has grown relatively narrow, these four papers seek to stretch it back out and all four are (as befitting our topic) forward-looking. Although the papers cover several different issues, I am going to shoe- horn them into that pre-conceived category-the future of philosophy of religion-and then focus on the parts of the papers central to that category and ignore the other parts that don't fit that template. This will not do justice to the complexity of the reality I am describing, but this procrustean practice is not unusual in philosophy of religion
\end{abstract}

Given the focused topic, I think that the papers do focus on a real problem in Religious Studies, namely, the provincial and uncooperative character of traditional philosophy of religion, and all four papers explore important options for the field. Ivan Strenski proposes that philosophers of religion revise their understanding of what they mean by "religion" and suggests that they emulate the model of political philosophy. Similarly, Bryan Rennie sees value in the cooperation between the history and philosophy of science as a model for how philosophy of religion might cooperate with history of religions. Greg Alles provides an exemplary illustration of what philosophy of religion could do if it did not assume "religion" as a reified object of study. And Marsha Hewitt wants to build bridges between philosophy of religion and the cognitive and neurosciences. Together the four papers provide a wealth of ideas for the future of the discipline.

\section{Ivan Strenski and the Philosophy of Lived Religion}

I judge that philosophy of religion in the future should work to create much better relationshipswith the disciplines in the study of religion outside philosophy of religion. It is therefore especially appropriate to begin the discussion of possible futures for philosophy of religion with the views of a historian of religions like Ivan Strenski. And it is not surprising that 
Strenski's view is an indictment of how philosophy of religion is presently pursued.

Strenski says that in the phrase "philosophy of religion," both the term "philosophy" and the term "religion" need to be analyzed. Let's start there. By "philosophy," Strenski refers to analytic philosophy. Strenski is right that analytic philosophy of religion has a truncated understanding of religion. In the last twenty-five years analytic philosophy of religion has largely taken as its object of study the rationality of theism. The central questions in analytic philosophy of religion textbooks, classes, and journals concern whether one can prove that God does or does not exist, whether the belief in God's existence can or cannot be reconciled with the reality of evil in the world, the relationship between faith in God and reason, and the problem of miracles as violations of the laws of nature. Moreover, it is not unusual for analytic philosophy of religion textbooks to work on issues drawn specifically from Christian theology: the nature of God (omniscience, omnipotence, etc.), prayer, revelation, the existence of the soul. Analytic philosophers of religion often describe what they do as the study of "generic theism," by which they mean that they investigate issues that are common to theists generally, whether they are Jews, Christians, Muslims, or Hindus. But I think that in this claim they are either lying or self-deceived. The issues that dominate their work are more accurately described as the aspects of Christianity that overlap to a greater or lesser extent with other Abrahamic traditions. Despite the occasional appearance of a Maimonides or an Ibn Sina, one almost never sees analytic philosophers of religion working on issues central to non-Christian theisms: nothing on pilgrimage, or fasting, or keeping God's law, let alone on possession or on prophecy (even though these things are found in Christianity). Thus Strenski is right that analytic philosophy of religion is largely shaped by the interests of Christian theology.

Strenski limits his critique to analytic philosophy of religion, and does not indict Continental philosophy of religion. I would like to do this for him. I take John Caputo, a dean of Continental philosophy of religion, as emblematic. Caputo defines religion as "the love of God." What is distinctive about this definition is that it focuses on love and thereby brings into philosophy of religion all of the phenomenological aspects of the religious affections. But clearly by defining religion in terms of God, this approach is no more inclusive of the varieties of religions around the world; it is still masquerading as generic theism. Strenski's suggestion that "the sacred" would be a more inclusive way to understand the object of religious affections is a step in the right direction.

Now, Strenski's primary critique of philosophy of religion is that it assumes what he calls a cognitivist definition of religion; that is, it defines religion in terms of religious words, beliefs, creeds, confessions, and other forms of religious discourse. Analytic philosophers of religion presume that what matters about religions is the propositions that religious people assume or assert. Strenski recommends that philosophers of religion instead take as their proper object "lived religion," including affiliation, material culture, practices, emotional life, bodies and culture. My own view is that the discursive or propositional element (the "beliefs") cannot be removed from a decisive place in lived religion; in other words, I agree with the historian of religions Bruce Lincoln that religious practices are defined as those "whose goal is to produce a proper world and/or proper human subjects, as defined by a religious discourse to which those practices are connected" (2003: 6). For something to be a religious practice, it will by definition be informed by a religious belief, and so the discursive is still central.

Perhaps Strenski would welcome the following friendly amendment to his recommendation. $\mathrm{He}$ is absolutely right that philosophers of religion in general have a truncated understanding of its object. Insofar as philosophy of religion assumes that what is essential is creeds (like those compiled by Jaroslav Pelikan), or theology, then they misunderstand what religion is. When they do this, philosophers disembody and deracinate religious beliefs from the practices, communities, and institutions that make up 
lived religion. Strenski is right to shine his spotlight on lived religion as the forms of life that give meaning to the discourse. Nevertheless, when philosophers of religion think that what is essential is propositions, they focus on what is, under some label or another, necessary for the study of any purposive behavior at all. To think about the relationship between propositions and behavior, consider this nonreligious example: if Linda looks at the sky and then grabs her umbrella, one might gather that she believes the proposition, "It may rain." But to focus on this proposition or this belief need not be to focus exclusively on explicit statements or on conscious beliefs-it can be to focus on and make sense of the looking and grabbing, that is, to make sense of the lived practice. I am proposing that the discursive dimension of religion is inevitable in the study of religions because it is inevitable in understanding human action generally. (For a defense of this claim, see Godlove, 2002.) Thus to accept Strenski's recommended focus on lived religion will not mean that philosophers of religion no longer study beliefs or propositions, though it will mean that they no longer study them in a "cognitivist" manner.

Strenski's argument is that as philosophers' understanding of religion changes, the philosophy of religion changes with it. I want to follow his path here and show where I think it leads. In one sense Strenski is right: if the object studied changes-from abstract words and beliefs and propositional attitudes to lived religion, including affiliation, material culture, practices, emotional life, bodies and culture-then the products of philosophy of religion certainly will be different. But will the practice of philosophy of religion also be different? If I look through a telescope at the moon and then I change the object that I am investigating to the planet Mars, then my account of the object will be different-that is true. But the telescope does not change. The tool of investigation has not changed. So my question is whether a change in the object of philosophy of religion requires philosophers to change what they do, and, if so, how. The other papers in this issue are helpful precisely here. What philosophers of religion do has traditionally been to investigate the rationality of religion. At the minimum, then, analytic philosophers of religion (and, to a lesser extent, Continental philosophers of religion) have to develop new vocabulary for bodies, practices, emotions, etc. The good news is that philosophy is growing in precisely this way: philosophical trends over the last century, including existentialism, pragmatism, action theory, Marxist philosophy, and feminist philosophy, have largely been anti-Cartesian. There has been a powerful philosophical turn to practice (for some summative examples, see Bernstein, 1971; Schatzki et al., 2001; Schilbrack, 2004). The bad news is that word has not yet reached philosophy of religion.

In my original response to Strenski, I pointed out that the word "of" in the phrase "philosophy of religion" can have two senses: there is an objective genitive sense in which the second noun is the object of the first. One sees this sense in phrases like "the throwing of the ball." And there is a subjective genitive sense in which the second noun is the subject of the first. One sees this sense in phrases like "the future of the planet." The "of" in philosophy of religion can likewise be taken in both senses. Let's call the latter, subjective sense: "religious philosophy." The question then is whether religion is the object of philosophy or whether it can also be the subject who is doing philosophy. Strenski says that he thinks that philosophy of religion should "steer clear" of religious philosophy. For Strenski, religion in the academy can only be the object and not the subject of philosophical investigation. He owes us an argument for that. I won't enter into this debate in this paper, but I would like to point out that, though Strenski's position is widely held, providing an argument that excludes religion as a subject in the academy-especially given the breakdown of the secularization hypothesis-is going to be difficult to do.

So, what would a philosophy of lived religion actually do? Strenski helpfully ends his article with a series of questions that could be the focus of the reconceived discipline. But empirical, explanatory questions are typically not philosophical. My sense 
is that what Strenski identifies is not the questions that will motivate the future of philosophy of religion precisely, but rather areas where philosophy of religion can and should work in an interdisciplinary way. Nevertheless, I judge that the philosophers who accept Strenski's suggested questions will be those who are most relevant to the future of Religious Studies.

\section{Greg Alles and the Kind of Concept "Religion" Is}

Greg Alles distinguishes between three different ways of sorting things in the world: "kinds," "classes," and a new category that he proposes, which he calls "clumps." Religions lack the properties found in those things that we sort into kinds and classes, he suggests, and so religion might be therefore better understood as a clump.

This is a novel suggestion. In weighing it, one can simply agree at the beginning that religions are not, like frogs or lightning or water, natural kinds. Undergraduates might accept the existence and nature of religions unreflectively, as simply part of the architecture of the world, but theorists don't assume that religions are natural kinds. More importantly, theorists of religion also do not even claim that religions are "natural," as opposed to historically emergent, socially realized human realities. Like art or politics, religion is a cultural reality. (The quotation in Marsha Hewitt's paper that belief in supernatural beings is an innate property of the human mind may come close to the claim that religion is natural, but I leave that argument to cognitive scientists to make.) To call religion a class, however, is widespread: most theorists of religion do think of religions as a class-for example, as a class of social activity, like business or politics.

For this reason, the central question of Alles' paper is whether religion is really not a class but rather a clump. Or to put the point epistemically: the central question of this paper is whether it is helpful to us as scholars of religion to speak of religions as a clump instead of as a class.

There is, however, a prior question that needs some attention: do clumps exist? One might conclude Alles' paper unsure, I think, because some of his examples of things that are supposed to be clumps are weak. One of his examples of a clump is "cups." I think that cups do have a property that they all share-in our original presentation of our papers, I suggested that it is something like this: cups are concave devices for holding things. "Concave devices for holding things" is, then, a class of objects that includes cups, and it therefore would also include subclasses such as drinking cups and athletic cups and trophy cups. And each of these subclasses of cups includes sub-subclasses, such as coffee cups and paper cups, or soccer trophy cups and hockey trophy cups. Alles worries that cups fail to share a common property, and he gives counter-examples. But I was not persuaded by them: he speaks of athletic cups and the cups in brassieres, but these examples seem to me to illustrate (in fact, to illustrate perfectly) a subclass of "cups" and not to trouble the coherence of the class of concave devices for holding things. To speak of folding a leaf so that one can use it as cup, asAlles did in his original paper, also fails to serve as a counter-example. Alles points out, correctly, that the World Cup is a soccer game and not a concave device for holding things. But I think that this example of a game that "is" a cup can be easily explained as synecdoche, as when we speak of "serving the crown" or say that "Washington made a statement" without implying that one submits to hats or that cities can talk. There is a trophy, and the trophy has a goblet-like cup on it because such cups came to be assimilated to victory - and then the game in which one wins that trophy is called, synecdochically, a World Cup. This use of "cup" is not unrelated to the prototypical use, and so it does not seem illuminating to call a drinking cup and the World Cup a clump.

Despite the fact that I am not persuaded by Alles' examples, however, I actually am 
persuaded by his central idea. For surely there are clumps. We say, "There is a clump of people over there." Or "I pulled out a clump of weeds." These examples illustrate, I think, the paradigmatic use of the term: a set of objects is treated together because they are physically aggregated. Alles is right that this kind of thinking on the fly would have cost-saving benefits for a brain and therefore evolutionary advantages.

So here is the central question: Can we also speak of a clump, as Alles suggests, as a set of objects that is treated together because they are conceptually aggregated? Or is it the case that, if a group of objects can be conceptually aggregated-items brought in from near and far according to the categorization of the thinker-that automatically makes the group a class? Remember, Alles rightly says: if the members of the set are collected because they share any substantive or functional property, then they are a class and not a clump.

This is a fascinating question. But here I was persuaded by one of Alles' examples: schizophrenia. I believe that the debate continues about whether schizophrenia is a single disease or a cluster of diseases. But if it turns out that the concept should be, as he says of religion, "fractionated" and that the different afflictions presently labeled schizophrenia have different etiologies and different remedies, then I think that it makes sense to reverse the reification of schizophrenia and to deconstruct and fractionate the conceptin which case we would be left not with a class of afflictions related to each other substantively or functionally, but simply a clump of diseases whose only common feature is that they had previously been assimilated to schizophrenia. (Presumably, each affliction would still be a member in the class of mental illnesses.) Therefore, I think that if a set of things is conceptually aggregated not because it has properties in common but only for the ease of the observer, then it does make sense to take advantage of Alles' proposal and to speak of it as a clump.

Now, if this idea of a conceptual clump works, the question is whether we want to say that religion constitutes a clump or whether it is better seen, as most theorists have seen it, as a class. Let's clarify this notion that religions constitute a class. One treats religions as a class when one identifies some belief or practice or institution as religious because it involves some substantive property (such as belief in superhuman agents). One also treats religions as a class when one identifies some belief or practice or institution as religious because it involves a certain functional property (such as giving a purpose to the individual's life, or giving order and coherence to society, or orienting values according to an ultimate concern). One also treats religion as a class when one identifies something as an instance of religion polythetically as a set of substantive properties (as in Herbert of Cherbury's Five Articles), or polythetically as a set of functional properties (as in Freud's mixture of psychological and social benefits of religion), or as a set that combines substantive and functional properties (as in Geertz's multi-part definition, which includes both models of the world and models for the world, both metaphysical beliefs and ethos). All of these kinds of theories conceive of religions as sharing properties of some kind and so all of them conceive of religions as members of a class.

How does one make this decision about the class/clump status of religion? From my perspective, questions about defining religion have to be answered pragmatically. As Peter Berger writes, 'Definitions cannot, by their nature, be either 'true' or 'false,' only more useful or less so" (1967: 175). The question is therefore not (though Alles sometimes sounds like this) whether religion is really a class or really a clump. The question is: is it useful to think of religion as class or clump? Alles does not put the decision in this way and he points out that one cannot simply stipulate the definition of, say, water. But this chemistry counter-example is question-begging, I believe: one cannot stipulatively define water, but that is because water is a natural kind. But one can stipulatively define classes. That is, if one wants to aggregate a set based on some property, one can-and then one can define it. For example, one can say that: "all my friends from high school" 
is a set. The members of the set share a common property and so this aggregation is a class and not a clump. Similarly, one can say: "I want to talk about all the practices and institutions that include belief in superhuman agents, and that is how I define religion." If one finds that definition useful, it would not be fair to say that religion cannot be defined this way because religions "really" have no property in common.

This is a paper-provocative in the best sense-and my brief response hardly settles the issue. Alles rightly says that discussions have not paid much attention to the kind of concept "religion" is. As the study of religions in the twenty-first century seeks to articulate a working definition of its subject matter in the light of the dizzying variety of data and the contradictory proposals about how to organize it, future discussions would do well to begin with the analysis that this paper provides.

\section{Bryan Rennie and the Religious Studies: Science Studies Analogy}

Rennie proposes an analogy: just as science studies not only can combine but have already successfully combined historical inquiry and philosophical inquiry into science, Religious Studies can similarly combine historical inquiry and philosophical inquiry into religion. I see two implications of his proposed analogy, both of which are significant and ought to become the foci of future debates about method in the study of religions.

In the first place, Rennie's proposal is more sophisticated than simply saying "let's do both." His proposal, as I understand it, is that the history of religions and the philosophy of religions mutually imply each other. He writes that the attempt to write history must be informed by philosophy, just as much as the attempt to write philosophy must be informed by history. The two approaches involve each other: it is not possible to do history (of science or of religions) without being informed by philosophy, and it is not possible to do philosophy (of science or of religions) without being informed by history. Consequently, as he put it in his original paper, [g]ood history and philosophy of religions is work that is both historical and philosophical at the same time.

In his vision of integration, Rennie is pointing Religious Studies in the right direction. And we should keep in mind that this is not a struggle to connect two different departments, because historical and philosophical approaches both resurface in both departments: we all know the professor who teaches the history of philosophy classes who keeps insisting that history matters to philosophy. And there are scholars in the history of religions programs who keep insisting that their fellow historians need to clarify their concepts. (Strenski and Alles are good examples!)

Rennie's proposal is here directed to philosophers of religion who are guilty (as Strenski also points out) of deracinating the religious object they study from its historical, social, and practical bed. But in a time when many historians and social scientists want to avoid or exclude philosophy's normative questions (including Strenski, as he seeks to keep at bay what he calls speculative philosophy), it is equally important to make the case for the inexpungibility of normative thinking. To make this case, Rennie needs to develop an explanation of how history and philosophy inform each other. He writes, citing David Hess, that each field has "a unique contribution to make" (Hess, 1997: 4), but he does not spell out what this contribution is. Rennie quotes Hess that in "a productive dialogue between philosophical and social studies outlooks ... philosophy may be helpful to social scientists and humanists when they are in the prescriptivemode, and likewise the research of social and cultural studies may be helpful to philosophers when they are making descriptive claims" (Hess, 1997: 8). I think that this is right. But philosophy "may be helpful" to historians-How?

My own way of addressing Rennie's point is to say that historians of religion presuppose their own answers to certain philosophical questions-questions about rationality, 
ontology, and value obviously permeate the work of historians and social scientists. For this reason, historians (even those who like to deny it) are entangled with philosophy, and philosophy is helpful to historians when they want to reflect critically on their own assumptions. Here is one quick example: historians seek to make sense of human actions, and therefore they presuppose-because they have to presuppose-answers to the questions about what it means for actions to make sense. So historians at least implicitly answer philosophical questions about rationality. And philosophers (even those who like to deny it) are entangled with history, and history is helpful to philosophers when they are doing the unavoidable work of interpreting what it is that a religious community is actually claiming. Any decision about the rationality of religious claims waits on and depends on what the claims mean, and meaning is a product of a specific historical context. In this way, philosophers at least implicitly presuppose the work of historians. This mutually implicatory view of the disciplines does not mean that history is really philosophy, or vice versa. But it does mean that history of religions cannot exclude philosophy, and that philosophy of religions cannot exclude history —and that neither side should want to. (For a more developed statement, see Schilbrack, 2005.)

Rennie's proposed analogy challenges the discussion about the future of philosophy of religion(s) in a second way. This second challenge concerns the place of secular reason in the study of religions, an issue that Rennie frames in terms of the insider/outsider question. The question is this: where do the scholars of religion themselves stand? It is unpersuasive to claim that scholars of religion are simply neutral or objective or scientific: scholars of religion either explicitly make or quietly assume their own views about what a human being is, what the universe holds, and what values are worth pursuing and these views inform their scholarship. For the most part, as Rennie rightly points out, those historians and social scientists who complain about the Christian and Western bias of philosophy of religion typically assume that the academy should follow a Western understanding of the good, the true, and the knowable. Rennie quotes Arvind Mandair's warning that "secular reason has been placed in a position of supervision in respect of any possible inquiry into religion" (Mandair, 2001: 50). This secularist assumption needs to be, as is said these days, "interrogated," and the discipline that critically reflects on basic assumptions about what is real, true, and worth pursuing is . . philosophy. The idea that Religious Studies ought not to include normative thinking is, on this account, hopelessly confused.

Rennie also calls for an integrated history and philosophy of religions that includes non-Western voices. This recommendation is inseparable from the point about interrogating secular reason, because non-Western voices are overwhelmingly not secular.

Rennie leaves open the question of whether an integrated history and philosophy of religions would represent a single, secular perspective that discloses this commitment to a particular set of values, or whether it should instead create a pluralistic approach in which multiple views are considered possible. This normative question has barely been addressed in Religious Studies, and Rennie is right that reflecting on it is a task that not only philosophers but also historians will need to address.

\section{Martha Hewitt and the Integrated Study of Religious Experience}

Martha Hewitt proposes that theories of religious experience are fuller and more accurate when they are informed by the neuro- and cognitive sciences and by psychoanalysis. One might therefore think of her recommendation for the future of philosophy of religion this way: as Rennie recommends that philosophers of religions should develop ties to the history of religions as philosophers of science have with the history of science, and Strenski recommends that philosophers of religion can look to those contemporary political philosophers who study not only political ideas but politics as it is lived, 
Hewitt is also nudging philosophers of religion to take advantage of some of the tools that are now emerging in a discipline other than their own, namely, the different branches of psychology.

One obstacle to joining philosophy of religion to psychological sciences of religion has been that some psychologists and cognitive scientists are reductionist in the sense that they see experiences and beliefs as exhaustively explained by the brain. If they are right, then there is not much left for philosophers of religion to do. Hewitt sees this obstacle and she wants to note that the reductionist program has not answered every question about experiences and beliefs. As she puts it, "much remains to be understood about the neurobiological basis of mind activity. Many leading neuroscientists agree that there remain a number of outstanding questions concerning mind/brain isomorphism." This is right, and I think that it is actually an understatement. This is why Alva Noe opens his recent book on the biology of consciousness with the following statement: "After decades of concerted efforts on the part of neuroscientists, psychologists, and philosophers, only one proposition about how the brain makes us conscious-how it gives rise to feeling, subjectivity-has emerged unchallenged: we don't have a clue" (Noe, 2009: $\mathrm{xi})$. It is surprising how much there is still to be done here, how "open" and messy this field is. Anthony Chemero is persuasive when he describes cognitive science as an immature science in Thomas Kuhn's terms (Chemero, 2009: ch. 1).

What is promising about Hewitt's paper is that she argues that it is possible to reconcile the scientific, body-based or brain-based approaches and the philosophical or psychological mind-based approaches. But how does one reconcile them? Hewitt argues against those "contemporary theorists of religion [who assume that] . . . the exploration of the feeling/psychological dimension is somehow at odds with what for them is a function or expression of a scientifically explainable neuro-physiological phenomenon." She wants the feeling, the affective emotional aspects of religion, to be included along with the physiological. And she is right that having both of these is in fact a tricky balancing act that the field of cognitive science of religion has not perfected. There is a tension between phenomenological cognitive science (like that of Alva Noe or Shaun Gallagher) and eliminativist cognitive science (like that of the Churchlands or Steven Stich). The eliminativists want to drop not only feelings or desires but the very category of the mental. Hewitt's insistence that the two can be reconciled is therefore welcome-though she herself does not show how they can be reconciled. Why do eliminativists reject the beliefs and desires that according to folk psychology constitute the mental life? Why are they uneasy about including emotions and other mental entities? Hewitt proposes that "compounding this unease is an underlying anxiety that a psychological/phenomenological approach conceals a theological interest, which seeks to establish that the mind is 'designed' to apprehend an already existing supernatural reality." That eliminativists reject theology is plausible. But even if a psychological/phenomenological approach makes no appeal at all to supernatural entities, eliminativists will oppose it. This is because the exclusively physiological cognitive scientists worry that a psychological/ phenomenological approach conceals a view that thoughts are anything other than physical realities completely understood and explained by biochemistry and neuroscience. In other words, the worry is that a psychological/phenomenological/philosophical approach (like the one Hewitt is recommending) conceals not a theological interest that includes God, but a humanist interest that includes beliefs, desires and emotions. This means that those who accept Hewitt's proposal have to make a case for the inexpungibility of human meanings for the study of the mind. Hewitt calls for "dialogue" between neuroscience and the humanities. My own view is that dialogue is not what is needed. What is needed is that those scholars who hold that beliefs, desires and emotions are central to human behavior-like me and, I think, like Hewitt—have to argue that the eliminativists are wrong to exclude these. (This is a place for common cause between psychologists of religion and those theologians who defend the more-than-chemicals aspects of religious behavior-like Don Browning's Religious Thought and the Modern Psychologies; 
in other words, there seems to be an appropriate strategic alliance between, on the one hand, historians, social scientists, and philosophers who want to defend the humanities, and on the other, theologians who also want to do so-a point to which I will return.) Thus instead of saying: "an inquiry into the psychological significance of religious experience is entirely compatible with neurobiological approaches," one should say: "an inquiry into the psychological significance of religious experience is entirely compatible with some neurobiological approaches" or " . . with nonreductive neurobiological approaches."

In general, Hewitt's recommendation that philosophers of religion develop connections with neuropsychology, cognitive science, and psychoanalysis is original and welcome. I have one concern. The concern is that the paper says that religions "provide a vivid sense of harmony and peace within oneself and with the universe." This seems one-sided. What of religious paths that promote self-abasement and mortification? Or those that teach the rejection of society-or even violence? What of wrathful and capricious deities? Stewart Guthrie (1993) has a nice critique of what he calls the comfort model of gods, and Hewitt's bridge-building to the psychological approaches to the study of religions will be stronger if it includes that. In the end, however, the thesis of Hewitt's paper is that a psychological inquiry and, presumably, a philosophical inquiry into the nature of religious experience in its varied and diverse expressions in specific historical cultural contexts should include "neurobiological, emotional, evolutionary-psychological, psychoanalytic, and cognitive perspectives." A rich understanding of religious experience like this ought to be the future of the field.

\section{References}

Berger P (1967) The Sacred Canopy: Elements of Sociological Theory of Religion. New York: Doubleday.

Bernstein R (1971) Praxis and Action: Contemporary Philosophies of Human Action. Philadephia: University of Pennsylvania Press.

Browning DS (1987) Religious Thought and the Modern Psychologies: A Critical Conversation in the Theology of Culture. Philadelphia: Fortress.

Caputo J (2001) On Religion. New York: Routledge.

Chemero A (2009) Radical Embodied Cognitive Science. Cambridge, MA: MIT Press.

Godlove TF Jr (2002) Saving belief: On the new materialism in religious studies. In: Frankenberry N (ed.) Radical Interpretation in Religion. Cambridge, UK: Cambridge University Press.

Guthrie S (1993) Faces in the Clouds: A New Theory of Religion. Oxford: Oxford University Press.

Hess DJ (1997) Science Studies: An Advanced Introduction. New York and London: New York University Press.

Lincoln B (2003) Holy Terrors: Thinking about Religion after September 11. Chicago: University of Chicago Press.

Mandair A-PS (2001) Thinking differently about religion and history: Issues for Sikh studies. In: Shackle C, Singh G, Mandair A-PS (eds) Sikh Religion, Culture and Ethnicity. Richmond: Curzon, 47-71. 
Noe A (2009) Out of our Heads: Why You Are Not Your Brain, and Other Lessons from the Biology of Consciousness. New York: Hill \& Wang.

Schatzki, TR, Cetina KK and von Sevigny E (eds) (2001) The Practice Turn in Contemporary Theory. New York: Routledge.

Schilbrack K (2004) On the use of philosophy in the study of rituals. In: Schilbrack K (ed.) Thinking through Rituals: Philosophical Perspectives. New York: Routledge.

Schilbrack K (2005) Bruce Lincoln's philosophy. Method and Theory in the Study of Religion 17(1): 44-58. 